\title{
Prevalence of khat chewing during pregnancy in Ethiopia: a systematic review and meta-analysis
}

Berhanu Boru Bifftu ( $\sim$ berhanuboru@gmail.com )

\section{Research article}

Keywords: Ethiopia, Khat chewing, Pregnancy, Women

Posted Date: June 8th, 2020

DOI: https://doi.org/10.21203/rs.3.rs-30563/v1

License: (ㅇ) (i) This work is licensed under a Creative Commons Attribution 4.0 International License. Read Full License 


\section{Abstract \\ Background}

Khat (Catha edulis) is a flowering green plant mainly chewed for recreational. Khat chewing is becoming on rising at alarming rate and adversely affects the socio-economic, psycho-social, and physical health including the health of the fetus. Thus, this study aimed to determine the pooled prevalence of khat chewing during pregnancy and its associated factors.

\section{Methods}

Databases: PubMed/Medline, CINAHL, SCOPUS and AJOL were searched. Weighted inverse variance random-effects model was used to calculate the pooled prevalence of depression. Heterogeneity across the studies was assessed by Cochrane chi-square and quantified by $\mathrm{I}^{2}$ statistics test. Funnel plots and Egger's test were used to determine publication bias. Sensitivity test and subgroup analysis were also performed.

\section{Results}

In this study, a total of 9,915 study participants were included from 22 studies. The pooled prevalence of khat chewing was found to be $20 \%(95 \% \mathrm{Cl} ; 14 \%-27 \%)$. Tests of heterogeneity demonstrated evidence of heterogeneity $\left(I^{2}=98.46 \%, p<0.001\right)$. However, the analysis of sensitivity tests and publication bias showed absence of influential study and publication bias [Egger's test $(P=0.02)$ ]. Factors such as: being Muslim, lower educational status, family history of mental illness, and partner previous history of khat chewing were associated with khat chewing.

\section{Conclusion}

One in five pregnant women has history of khat chewing. Thus, authors' suggest the need of screening for khat chewing as an integrated part of Antenatal care.

\section{Background}

Khat (Catha edulis) also known as qat, chat, African salad, Abyssinian tea, and African tea, is a flowering green plant containing a natural amphetamine like stimulant called amphetamine (1-3). Khat chewing practice is rapidly increasing worldwide and currently an estimated of 20 million people chew khat $(4,5)$. In East Africa, $18-90 \%$ of male and $10-60 \%$ females chew khat on a daily basis(6-9). In Ethiopia, chewing of khat is becoming habitual and increasing at an alarming rate with an estimated prevalence ranged from $30 \%$ to $50 \%$ (10-13). According to 2016 Ethiopia Demographic and Health Survey (EDHS), around $27 \%$ of men and $12 \%$ of women had history of khat chewing (14) with up to $65 \%$ during pregnancy (15-31). Khat chewing has different socio-economic, psycho-social, physical and environmental impact $(1,5,12,13,32)$. 
Inaddition to these adverse effect, the practice of chewing khat go beyond the life of the pregnant women and affect the neonate $(15-18,33,34)$ by reduced daily food intake, anaemia, low birth weight and to the extent of maternal and infant death $(15-18,33,34)(19,20,35-37)$. Factors such as: peer pressure, accessibility, acceptability, and cultural beliefs of relief for headache, weight loss and assistance during birth were associated with khat chewing during pregnancy (15, 17-20). However, Ethiopian government had an initiative to control the adverse effect of substance use for cigarette smoking, but there is no similar action for khat use. However individual studies is is important and showed the existence of khat use among pregnant mothers, the inconsistence of reported epidemiological finding need a comprehensive up to date information for all concerned bodies and the focus of most of the available studies were among the general population and college students. To the authors' knowledge, there is no systematic review and metaanalysis that address this gap. Thus, the main purpose of this systematic review and meta-analysis was to determine the pooled prevalence of khat chewing during pregnant and synthesize its associated factors in Ethiopia.

\section{Methods}

\section{Search strategy}

Databases such as: PubMed/Medline, CINAHL, AJOL and SCOPUS were searched using the search terms: (khat OR Catha edulis OR khat use OR khat consumptions OR khat chewing OR khat abuse OR khat dependence OR khat use disorder OR substance OR substance use OR psychoactive substance OR substance use disorder OR substance abuse) AND (prevalence OR incidence) OR magnitude) AND (factors OR risk factor OR risk OR determinant) AND (maternal OR mother OR primigravida OR wom*n OR pregnant OR prenatal) AND Ethiopia for PubMed/MEDLINE. A Google scholar search was also performed. We formulated a comprehensive search strategy by the combination of Medical Subject Headings (MeSH) thesaurus, text words, and appropriate Boolean Operators tailored to each database. No time and language restrictions were imposed on the search strategy. Reference lists of all articles were searched. Moreover, Google Scholar was searched for gray literature. All searches were performed until August-14-2019. Similarly, CINAHL, AJOL and SCOPUS were searched. using similar search terms tailored to each database. We adhered to the Preferred Reporting Items for Systematic Review and Meta-Analysis (PRISMA) (38).

\section{Selection of studies}

All studies retrieved through search strategy were imported to EndNote X7 (Thomson Reuters, New York, USA) then, duplicated studies were removed from EndNote Library. The title and abstracts of the remaining articles were assessed independently by two reviewers (BBB and YDG). Disagreements were resolved by taking the mean score of the two reviewers.

\section{Definition of concepts}

In this study, khat use during pregnancy is defined as use of khat (any amount) at least once.

\section{Eligibility Criteria}


Setting: This review included studies carried out in Ethiopia.

Participants: This review included the results of khat use and its associated factors that assessed during pregnancy.

Outcome measure: This systematic review and meta-analysis have two main outcomes. The first outcome was to determine the pooled prevalence of khat use during pregnancy. The second outcome of the study was to identify factors associated with khat use. Prevalence was calculated by dividing the number of khat chewer during pregnancy to the total number of pregnant women included in the study (total sample size) multiplied by 100 . For the associated factors, the reported odds ratio, $95 \%$ confidence interval and $p$-value were used to tabulate and described the results thematically.

Study design: Observational studies (cross-sectional and cohort/longitudinal) were included. Studies that focused on case reports, conference and abstracts were excluded if the required data are not accessed.

\section{Data extraction}

Data were extracted from the eligible studies using a pre-conceived and piloted data abstraction form. Data were simultaneously extracted by two independent reviewers (BBB and YDG). The extracted data include: name of the first author last name, year of publication, study area/region, study design, sample size, number of cases/prevalence and associated factors.

\section{Quality assessment}

The Newcastle-Ottawa quality assessment tool, adapted for cross-sectional studies (39) was used for quality assessment. This tool had three main parts (selection, comparability and outcome). The first part (selection) has five stars and assesses the methodological quality of the study. The second part of the tool evaluates the comparability of the study. The third part of the tool assesses the quality of the original article's outcome with respect to the statistical analysis. Individual paper was graded with score ranged from zero to ten stars. The overall quality of each article was determined using the sum of each star of the three parts and defined as high quality for score $\geq 6$ out of 10 , medium (fulfilling $50 \%$ of quality assessment criteria) and poor for $<4$.

\section{Data synthesis and statistical analysis}

The extracted data were entered into a Microsoft Excel Database and then imported into STATA version 14 (Stata Corp LLC, Texas, USA) software with packages of Meta-analysis for analysis. Meta-analysis was performed with STATA 14 using the "Metaprop" command with random-effects models to calculate the pooled effect size at 95\% confidence intervals (40) with the Dersimonian and Laird method based transformed values and their variance (41). The Freeman-Tuckey variant of the arcsine square root transformation of proportions was fitted to avoid variance instability when handling proportions close to one (42). Heterogeneity between studies was measured by the index of heterogeneity ( $1^{2}$ statistics) test (43). $\mathrm{I}^{2}$ statistics values of $25 \%, 50 \%$ and $75 \%$ was used as low, medium and high heterogeneity respectively. Subgroup analysis was performed by years of publication, study setting, study design, sample size and quality 
of included studies. Publication bias was examined by the visual inspection of funnel plot (44) and egger test (45) with p-value of $<0.05$ was considered as statistically significant. Sensitivity analyses was conducted to examine influential studies (46). However, we planned for meta-analysis of associated factors, because of the inconsistent and insufficient of data; results were analyzed thematically and presented using texts and table.

\section{Results}

The initial database literature search resulted in 954 published articles. Additional, 13 studies were located through other source. Finally, the overall literature search resulted in 967 articles. Of these articles, 678 were excluded during the initial assessments as their title and abstract were found to be irrelevant. Of the remaining 289 studies, 186 articles were excluded through abstract reading because of different outcome and unclear results. Finally, 81 papers were excluded because of different eligibility. Then, the remained 22 studies were included in the systematic review and meta-analysis (Fig. 1).

\section{Study characteristics}

In this study, a total of 9,915 study participants were included from 22 studies. These studies were carried out between 1997 to 2019 years in four different regions: Addis Ababa $(n=6)$, Amhara $(n=3)$, Oromia (10), and Southern Nation and Nationalities of People (SNNP) $(n=3)$. Majority $(73 \%)$ of the included studies are institution based cross-sectional study design. All studies presented data on self-report. The sample size of study participants ranged from 112 to 1065. The qualities of included studies were between 5 and 8 . Of these, majority $60 \%$ had an overall good quality and the remaining studies had fair quality (Table: 1 ).

\section{Prevalence of khat chewing}

The pooled prevalence of khat chewing was found to be $20 \%$ (95\% Cl; $14 \%-27 \%$ ) (Fig. 2). Tests of heterogeneity demonstrated evidence of heterogeneity $\left(I^{2}=98.46 \%, p<0.001\right)$. The analysis of sensitivity tests showed that none of the point estimates was outside of the overall $95 \%$ confidence interval confirming that: (i) there was no influential study and (ii) based on these 22 studies the pooled estimated prevalence of khat chewing was important. We did not find evidence of publication bias from the visual inspection of the funnel plot (Fig. 3) and Egger's test $(P<0.02)$ ].

\section{Subgroup analysis}

Overall, the highest and lowest pooled prevalence of khat chewing was reported from study with small sample size (<300) 33\% (95\% Cl: 15\%-55\%) and in Amhara region 12\% (95\% Cl: 3-27) respectively. For the remaining subgroup analysis by sample size, study design, study quality, publication year between and study setting, we observed, higher pooled prevalence among studies with smaller sample size (pooled prevalence $=33 \%$ (95\% Cl: 15\%-55\%), community based study design (pooled prevalence $=22 \%$ (95\% Cl: $12 \%-32 \%$ ), fair quality of study (pooled prevalence = 26\% (95\% Cl: 16\%-35\%), 2016-2019 publication year (pooled prevalence $=23 \%(95 \% \mathrm{Cl}$ : 15\%-32\%) and in SNNP region (pooled prevalence $=23 \%(95 \% \mathrm{Cl}$ : 
$12 \%-41 \%)$, as compared to studies with higher sample size, institution based study, good quality of study, before 2016 publication year and Oromia/Addis Ababa/Amhara region (Table 2). 
Table 1

Characteristics of the studies

\begin{tabular}{|c|c|c|c|c|c|c|c|c|}
\hline Authors & Year & Setting & Design & Outcome & $\begin{array}{l}\text { Sample } \\
\text { size }\end{array}$ & $\begin{array}{l}\text { No. } \\
\text { of } \\
\text { cases }\end{array}$ & prevalence & Quality \\
\hline Fekadu & 2017 & $\begin{array}{l}\text { Addis } \\
\text { Ababa }\end{array}$ & Institution & $\begin{array}{l}\text { Khat } \\
\text { chewing }\end{array}$ & 367 & 39 & 10.6 & Good \\
\hline S/Mariam & 1997 & $\begin{array}{l}\text { Addis } \\
\text { Ababa }\end{array}$ & Community & $\begin{array}{l}\text { Khat } \\
\text { chewing }\end{array}$ & 202 & 85 & 42 & Fair \\
\hline Abdurashid & 2013 & $\begin{array}{l}\text { Addis } \\
\text { Ababa }\end{array}$ & Institution & $\begin{array}{l}\text { Khat } \\
\text { chewing }\end{array}$ & 348 & 21 & 6 & Fair \\
\hline Hanlon & 2009 & Oromia & Community & $\begin{array}{l}\text { Khat } \\
\text { chewing }\end{array}$ & 1056 & 135 & 12.8 & Fair \\
\hline Teso & 2017 & Oromia & Institution & $\begin{array}{l}\text { Khat } \\
\text { chewing }\end{array}$ & 293 & 193 & 66 & Fair \\
\hline Smart & 2016 & SNNP & Community & $\begin{array}{l}\text { Khat } \\
\text { chewing }\end{array}$ & 1009 & 305 & 30 & Fair \\
\hline Tesfaye & 2013 & Oromia & Institution & $\begin{array}{l}\text { Khat } \\
\text { chewing }\end{array}$ & 336 & 120 & 36 & Good \\
\hline Eba & 2014 & $\begin{array}{l}\text { Addis } \\
\text { Ababa }\end{array}$ & Institution & $\begin{array}{l}\text { Khat } \\
\text { chewing }\end{array}$ & 412 & 27 & 6.6 & Good \\
\hline Jebena & 2015 & Oromia & Institution & $\begin{array}{l}\text { Khat } \\
\text { chewing }\end{array}$ & 642 & 369 & 57 & Good \\
\hline Demeke & 2014 & Amhara & Institution & $\begin{array}{l}\text { Khat } \\
\text { chewing }\end{array}$ & 420 & 25 & 6 & Fair \\
\hline Demlash & 2015 & Oromia & Institution & $\begin{array}{l}\text { Khat } \\
\text { chewing }\end{array}$ & 387 & 48 & 12 & Good \\
\hline Wachamo & 2019 & Amhara & Institution & $\begin{array}{l}\text { Khat } \\
\text { chewing }\end{array}$ & 360 & 27 & 7.5 & Good \\
\hline Nakajima & 2017 & Oromia & Institution & $\begin{array}{l}\text { Khat } \\
\text { chewing }\end{array}$ & 642 & 123 & 19 & Good \\
\hline Aderaw & 2018 & SNNP & Community & $\begin{array}{l}\text { Khat } \\
\text { chewing }\end{array}$ & 341 & 122 & 36 & Good \\
\hline Tefera & 2015 & Oromia & Community & $\begin{array}{l}\text { Khat } \\
\text { chewing }\end{array}$ & 340 & 20 & 9 & Good \\
\hline Tesfaye & 2018 & Oromia & Institution & $\begin{array}{l}\text { Khat } \\
\text { chewing }\end{array}$ & 336 & 60 & 18 & Good \\
\hline Ahmed & 2018 & Amhara & Institution & $\begin{array}{l}\text { Khat } \\
\text { chewing }\end{array}$ & 297 & 83 & 28 & Fair \\
\hline
\end{tabular}

SNNP: Southern Nation and Nationalities of People 


\begin{tabular}{|lcllllllll|}
\hline Authors & Year & Setting & Design & Outcome & $\begin{array}{l}\text { Sample } \\
\text { size }\end{array}$ & $\begin{array}{l}\text { No. } \\
\text { of } \\
\text { cases }\end{array}$ & prevalence & Quality \\
\hline Obse & 2013 & Oromia & Institution & $\begin{array}{l}\text { Khat } \\
\text { chewing }\end{array}$ & 374 & 57 & 15 & Good \\
\hline Negewo & 2019 & Oromia & Institution & $\begin{array}{l}\text { Khat } \\
\text { chewing }\end{array}$ & 228 & 20 & 8.8 & Good \\
\hline Dendir & 2017 & $\begin{array}{l}\text { Addis } \\
\text { Ababa }\end{array}$ & Institution & $\begin{array}{l}\text { Khat } \\
\text { chewing }\end{array}$ & 112 & 32 & 28.6 & Fair \\
\hline W/amanuel & 2018 & $\begin{array}{l}\text { Addis } \\
\text { Ababa }\end{array}$ & Institution & $\begin{array}{l}\text { Khat } \\
\text { chewing }\end{array}$ & 348 & 45 & 13 & Good \\
\hline Senturk & 2012 & SNNP & Community & $\begin{array}{l}\text { Khat } \\
\text { chewing }\end{array}$ & 1065 & 137 & 13 & Fair \\
\hline SNNP: Southern Nation and Nationalities of People & & & & \\
\hline
\end{tabular}


Table 2

Subgroup analysis by sample size, study quality and publication year

\begin{tabular}{|c|c|c|c|c|c|}
\hline Subgroup & $\begin{array}{l}\text { Number of } \\
\text { Studies }\end{array}$ & Pooled prevalence & $95 \% \mathrm{Cl}$ & $1^{2}$ & P-value \\
\hline \multicolumn{6}{|l|}{ Study design } \\
\hline Institutional based & 16 & 0.19 & $0.11-0.28$ & 98.61 & $<0.001$ \\
\hline Community based & 6 & 0.22 & $0.12-0.32$ & 98.27 & $<0.001$ \\
\hline \multicolumn{6}{|l|}{ Sample size } \\
\hline$<300$ & 5 & 0.33 & $0.15-0.55$ & 98.36 & $<0.001$ \\
\hline$\geq 300$ & 17 & 0.16 & $0.11-0.23$ & 98.24 & $<0.001$ \\
\hline \multicolumn{6}{|l|}{ Study quality } \\
\hline Good & 13 & 0.19 & $0.12-26$ & 98.42 & $<0.001$ \\
\hline Fair & 9 & 0.26 & $0.16-0.35$ & 98.79 & $<0.001$ \\
\hline \multicolumn{6}{|l|}{ Publication year } \\
\hline 1997-2015 & 11 & 0.17 & $0.9-0.27$ & 97.80 & $<0.001$ \\
\hline $2016-2019$ & 11 & 0.23 & $0.15-0.32$ & 98.89 & $<0.001$ \\
\hline \multicolumn{6}{|l|}{ Study setting } \\
\hline Addis Ababa & 6 & 0.16 & $0.8-0.26$ & 96.67 & $<0.001$ \\
\hline Oromia & 10 & 0.23 & $0.12-0.36$ & 98.94 & $<0.001$ \\
\hline Amhara & 3 & 0.12 & $0.3-0.27$ & - & - \\
\hline SNNP & 3 & 0.25 & $0.12-41$ & - & - \\
\hline
\end{tabular}

\section{Factors associated with khat chewing}

\section{Narrative review}

Based on this review, limited number of studies reported about the factors associated with khat chewing. So, results were synthesized thematically under: socio-demographic, psychological, and behavioral related factors.

\section{Socio-demographic factors}

Being Muslim ( $O R=24, p<0.001)$, illiterate $(O R=5.61, p<0.001)$, and primary education $(O R=3.55, p<$ $0.001)$ were associated with khat chewing (17). 


\section{Psycho-social}

Those pregnant women who had family history of mental illness were six times $(O R=6.33, p<0.001)$ more likely engaged in khat chewing. Moreover, those pregnant women who had history of khat chewing were around two times (AOR, $1.65 ; 95 \% \mathrm{Cl}, 1.10,2.47)$ more likely experienced CMDs (17). Those pregnant women who had history of khat chewing were around two times (AOR, $1.65 ; 95 \% \mathrm{Cl}, 1.10,2.47)$ more likely experienced CMDs (47).

Behavioral factors: Those pregnant women who had partner history of khat chewing were twelve times (OR $=12.4, \mathrm{p}<0.001)$ and those with history of violence were around three times AOR 2.901 (95\%Cl: $1.302-$ $6.463, P, 0.009)$ more likely engaged in khat chewing $(17,48,49)$.

\section{Discussion}

The main purpose of this systematic review and meta-analysis was to assess the pooled prevalence of khat chewing and its associated factors during pregnancy in Ethiopia. The present study indicated that one in five of pregnant women had history of khat use. This implies despite the international recommendation of pregnant women's abstinence to any substance (50), in Ethiopia, there is limitation in the implementations of internationally accepted measures for safe motherhood and infants. This may be attributed to the lack of knowledge toward the adverse effect of substance on the health mother and the fetus. In Ethiopia, there is a perception of khat use as medicine for headache, socialization, stress reduction and easy delivery that may be the reason for khat use (15-20). Even though similar studies are scarce, the results of this finding is within the reported prevalence of khat chewing in Yeme $(40.7-47 \%)(51,52)$. Previous meta-analysis showed that the association of khat chewing on birth weight (53), perinatal and young infant death, intrauterine growth retardation, low foetal birth weight (54), sleep disturbance and memory problems of pregnant women (20).

In the current systematic review and meta-analysis, however; the study level characteristics by subgroup analysis such: sample size, study design, study quality, publication year and study setting showed statistical significance; this implies the presence of other characteristics for the contribution of heterogeneity; the overall highest and lowest pooled prevalence of khat chewing was reported from study with small sample size [33\% (95\% Cl: $15 \%-55 \%)]$. This may be due to the research methodology, sociocultural norms and the availability of khat in the study area. For example, "Jimma" is the name of place in Ethiopia, Oromia region, as the same time, it is the common name for khat (place where its name is originated). This is consistent with other studies (15-20) and supported by EDHS $2011(10,11)$.

Regarding the associated factors limited number of studies identified socio-demographic, pregnancy related psychological and behavioural related factors of associated factors $(19,20,35)$. From this limited studies, we observed the scarcity of studies about factors associated with khat chewing that suggests the needs of future researchers to address this gap because identification of health determinant factors are important public health issues to design appropriate interventions.

\section{Strengths and limitations of the study}


To our knowledge, this is the first systematic review and meta-analysis about khat chewing among pregnant women in Ethiopia. To manage heterogeneity, bias and make the findings more meaningful, four different methods were performed. First; during analysis, we used appropriate model (a random effect model) to control the effects of the observed heterogeneity. Secondly; we conducted a leave one out sensitivity analysis to identify influential study. Third; we conducted subgroup analysis by sample size, study design, study quality, publication year and study setting. Finally, funnel and egger test was performed to identify small study effect. However, some limitations such as: use of reference lists and Google Scholar may have the possibility of having some overlooked articles and lack of similar study limited the discussion.

\section{Conclusion}

In Ethiopia, one in five pregnant women has experience of khat chewing. Factors such as: being Muslim, lower educational status, family history of mental illness, and pregnant women and partner previous history of khat chewing were associated with khat chewing. Thus, authors' suggest the need of pregnant women screening for khat chewing as an integrated part of ANC. Authors' also suggest the needs of strengthening awareness about the adverse effect of khat chewing.

\section{Abbreviations}

AJOL: African Journals Online; ANC: Antenatal Care; Cl: Confidence Interval; EDHS: Ethiopia Demographic and Health Survey; OR: Odds Ratio; PRISMA: Preferred Reporting Items for Systematic Reviews and MetaAnalyses; SNNP: Southern Nation and Nationalities of People.

\section{Declarations}

\section{Acknowledgements}

Authors' gratitude goes to University of Gondar for office arrangement and motivational support to conduct this systematic review and meta-analysis.

\section{Funding}

This research received no grant from any funding agency.

\section{Availability of data and materials}

All data in this study were included.

\section{Authors' contributions}

BBB designed the systematic review and meta-analysis in collaboration with YDG. BBB developed the search strategy and drafted the protocol. YDG improved the drafted systematic review and meta-analysis. BBB and YDG performed search strategy and conducted data selection and extraction. Both authors were 
involved in data analysis and interpretation of the results and write up the manuscript. Authors read and approved the final manuscript for publication.

\section{Ethics approval and consent to participants}

Not applicable.

\section{Consent for publication}

Not applicable.

\section{Competing interests}

None declared.

\section{Authors' information's}

${ }^{1}$ University of Gondar College of Medicine and Health Science, School of Nursing, Gondar, Ethiopia

${ }^{2}$ Bahar Dar University, College of Medicine and Health Science, Department of psychiatry.

\section{References}

1. Patel NB. Khat (Catha edulis Forsk) - And now there are three. Brain Research Bulletin 2019;145:92-6.

2. Lemessa. D. Khat (Catha edulis): Botany, Distribution, Cultivation, Usage and Economics in Ethiopia UNEmergencies Unit for Ethiopia. Addis Ababa, 2001. 2001.

3. P K. The Pharmacology of Khat. Gen Pharmac. Gen Pharmac. 1984;15:179-87.

4. Kassim S AaM. Khat use is a neglected addictive behaviour. Addiction. 2016;111:179-80.

5. Mihretu A. Definition and Validity of the Construct "Problematic Khat Use": A Systematic Review. Eur Addict Res 2019;25:161-72.

6. Kandela P. Women's rights, a tourist boom, and the power of khat in Yemen. Lancet. 2000:355, 1437.

7. Patel NB, et al., . Neurobiology of khat (Catha edulis Forsk). In: In: Bentivoglio, M. (Ed.), Neglected Tropical Diseases and Conditions of the Nervous System 307 @ Springer Science+Business Media, New York. https://doi.org/10.1007/978-1 2014.

8. AS E. The chewing of khat in Somalia. J Ethnopharmacol. 1983;8:163-76.

9. Aden A DE, Ndolo UM, Chindia ML. Socio-economic Effects of khat chewing in north eastern Kenya. East Afr Med J. 2006;83:69-73.

10. Haile D LY. Khat chewing practice and associated factors among adults in Ethiopia: further analysis using the 2011 demographic and health survey. PLoS ONE. 2015;10(6):1-8.

11. Harminder Guliani` SGaMÇ. Factors affecting tobacco smoking in Ethiopia: evidence from the demographic and health surveys BMC Public Health 2019;19(938):1-17. 
12. al. Me. What constitutes problematic khat use? An exploratory mixed methods study in Ethiopia. Substance Abuse Treatment, Prevention, and Policy. 2017;12(17):1-12.

13. Alemayehu Gashawa* TG. The Chemistry of Khat and Adverse Effect of Khat Chewing. American Scientific Research Journal for Engineering, Technology, and Sciences. 2014;9(1):35-46.

14. International CSACEal. Ethiopia Demographic and Health Survey 2016. Addis Ababa and Rockville: CSA and ICF; 2016. https://dhsprogram.com/pubs/pdf/FR328/FR328.pdf. 2016.

15. Demelash H, Motbainor A, Nigatu D, Gashaw K, Melese A. Risk factors for low birth weight in Bale zone hospitals, South-East Ethiopia : a case-control study. BMC pregnancy and childbirth. 2015;15:264.

16. Kedir H, Berhane Y, Worku A. Khat chewing and restrictive dietary behaviors are associated with anemia among pregnant women in high prevalence rural communities in eastern Ethiopia. PloS one. 2013;8(11):e78601.

17. Nakajima M, Jebena MG, Taha M, Tesfaye M, Gudina E, Lemieux A, et al. Correlates of khat use during pregnancy: A cross-sectional study. Addictive behaviors. 2017;73:178-84.

18. Manzar MD, Salahuddin M, Sony P, Maru TT, Pandi-Perumal SR, Moscovitch A, et al. Sleep disturbances and memory impairment among pregnant women consuming khat: An under-recognized problem. Annals of thoracic medicine. 2017;12(4):247-51.

19. MA A-A. Khat chewing during pregnancy: an insight on an ancient problem impact of chewing Khat on maternal and fetal outcome among Yemeni pregnant women. Ommega Int 2015;1(2):1-8.

20. Masood Muhammed SA AM. The impact of chewing Khat during pregnancy on foetal death history Int J Novel Res Healthc Nurs 2015;2(2):28-31.

21. Tesso FY WL, Kebede DB Magnitude of Substance Use and Associated Factors among Pregnant Women Attending Jimma Town Public Health Facilities, Jimma Zone, Oromia Regional State Southwest Ethiopia. Clinics Mother Child Health 2017, 14: 275 doi:104172/2090-72141000275.

22. Alehegn Aderaw BSASH. Caffeine, Alcohol, Khat, And Tobacco Use During Pregnancy In Butajira, South Central Ethiopia, Addis Ababa University, 2018.

23. Wachamo TM BYN, Bizuneh AD Risk factors for low birth weight in hospitals of North Wello zone, Ethiopia: A casecontrol study. PLoS ONE. 2019, 14(3): e0213054. https:// doi.org/10.1371/journal.pone.0213054.

24. al. Ae. A health facility based case-control study on determinants of low birth weight in Dassie town, Northeast Ethiopia: the role of nutritional factors. Nutrition Journal (2018) 17:103):1-10.

25. Niguse Obse1 AM, Teshome Gobena. Magnitude Of Anemia And Associated Risk Factors Among Pregnant Women Attending Antenatal Care In Shalla Woreda, West Arsi Zone, Oromia Region, Ethiopia . Ethiop J Health Sci.2013, 23 (2):1-7

26. MA T. Factors Associated with Hypertensive Disorder of Pregnancy in Kombolcha. Clinics Mother Child Health. 2017, 14: 274.doi:10.4172/2090-7214.1000274.

27. AN N. Prevalence of depression among pregnant women attending ANC follow up mother's at higher two health center, jimma teaching health center, shenen gibe hospital and jush, jimma town, oromia regional state, South West Ethiopia. Clinics Mother Child Health.2019;16:315. 
28. Dejene MTWAAT. Magnitude And Factors Associated With An Unintended Pregnancy Among Women Attending Antenatal Care In Addis Ababa, 2018.

29. al CSe. Fatigue as a symptom of psychosocial distress. Tropical Medicine and International Health. 2016, 21 (3): 365-372

30. Senturk V. Impact of perinatal somatic and common mental disorder symptoms on functioning in Ethiopian women: The P-MaMiE population-based cohort study. Journal of Affective Disorders 136 (2012) 340-349.

31. al KTKe. Burden of Helicobacter pylori Infections and Associated Risk Factors among Women of Child Bearing Age in Addis Ababa, Ethiopia. Hindawi International Journal of Chronic Diseases Volume 2018, Article ID 5183713, 10 pages https://doi.org/10.1155/2018/5183713.

32. Engidawork* E. Pharmacological and Toxicological Effects of Catha edulis F. (Khat).REVIEW. Phytother Res. 2017;31:1-10.

33. Kenfe Tesfay1 MAMWMT. Effect of Khat Use During Pregnancy on the Birth Weight of Newborn in Jimma, Ethiopia. Int J Ment Health Addiction.2018; 1-10.

34. al Je. Household food insecurity and mental distress among pregnant women in Southwestern Ethiopia: a cross sectional study design. BMC Pregnancy and Childbirth (2015) 15:250.

35. al AHA-Se. Maternal, prenatal and traditional practice factors associated with perinatal mortality in Yemen. Women and Birth. 2019;32:204-15.

36. Shuaib AA FK. Occurrence and risk factors of low birth weight in Sana'a, Yemen. JHIPH.47(1):1-12.

37. Eriksson M, Ghani, N. A., \& Kristiansson, B. Khat chewing during pregnancy-effect upon the off-spring and some characteristics of the chewers. East African Medical Journal. 1991;68:106-11.

38. Shamseer L MD, Clarke M, et al. Preferred reporting items for systematic review and meta-analysis protocols (PRISMA-P) 2015: elaboration and explanation. BMJ 2015;349:g7647.

39. Scale TN-O. adapted for cross-sectional studies.

40. Berkey CS HD, Mosteller F, Colditz GA. A random-effects regression model for meta-analysis. Statistics in medicine. 1995;14(4):395-411.

41. LN DR. Meta-analysis in clinical trials. Control Clin Trials Control Clin Trials. 1986;7(177-88).

42. TJ FM. Transformations related to the angular and the square root. AnnMath Stats. 1950;21(4):607-11.

43. Higgins JP TS. Quantifying heterogeneity in a meta-analysis. Statistics in medicine. Statistics in medicine 2002;21(11).

44. JL L. The role of the funnel plot in detecting publication and related biases in meta-analysis. Evidencebased dentistry. 2011;12(4):121-2.

45. Egger M DSG, Schneider M, Minder C. Bias in meta-analysis detected by a simple, graphical test. BMJ (Clinical research ed). 1997;315(7109):629-34.

46. Duval S T, R., . Trim and fill: a simple funnel-plot-based method of testing and adjusting for publication bias in meta-analysis. Biometrics 2000;56:455-63.

47. al Te. Perinatal depression and associated factors among reproductive aged group women at Goba and Robe Town of Bale Zone, Oromia Region, South East Ethiopia. Maternal Health, Neonatology, and 
Perinatology (2015) 1:12):1-9.

48. Ahmed RA. The Prevalence of Domestic Violence in Pregnant Women Attending Antenatal Care During Their Current Pregnancy at Selected Health Facilities in Addis Ababa. Ethiopia. 2013:1-13.

49. Desalegn TEaD. Pregnancy outcomes of gender based violence among pregnant women admitted to labor and delivery units in three teaching hospitals: A cross sectional study. A thesis Submitted to the School of Graduate Studies, Addis Ababa University, 2014.

50. Florence Thibaut ea. WFSBP and IAWMH Guidelines for the treatment of alcohol use disorders in pregnant women, . The World Journal of Biological Psychiatry, DOI: 101080/1562297520181510185. 2019.

51. Organization MoPaDaCS. Yemen Demographic and Maternal and Child Health Survey 1997 (YDMCHS). Sana'a, Yemen. 1998.

52. Saad MKAEMA-NaG. Khat (Catha edulis) Chewing during Pregnancy in Yemen: Findings from a National Population Survey. Matern Child Health J. 2007:1-5.

53. Hassen K. Khat (Catha edulis) chewing as a risk factor of low birth weight among full term Newborns: $A$ systematic review. MIDDLE EAST JOURNAL OF FAMILY MEDICINE 2015;13(7):1-5.

54. Mwenda JM, Arimi, M.M., Kyama, M.C., \& Langat, D.K. . Effect of khat (Catha edulis) consumption on reproductive function: A review. East African Medical Journal. 2003;80(6):262-67.

\section{Figures}




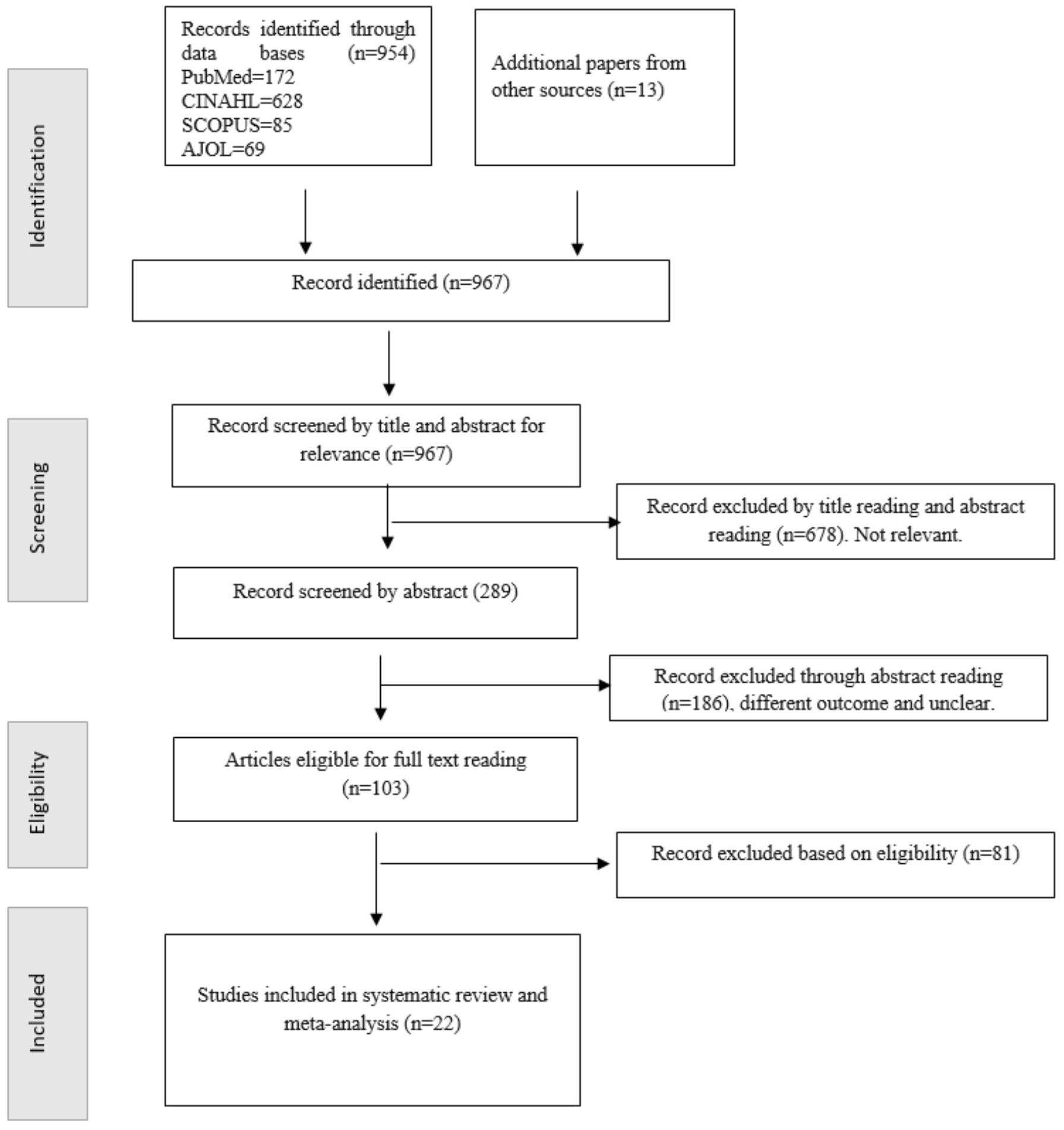

Figure 1

Flow diagram of included studies 


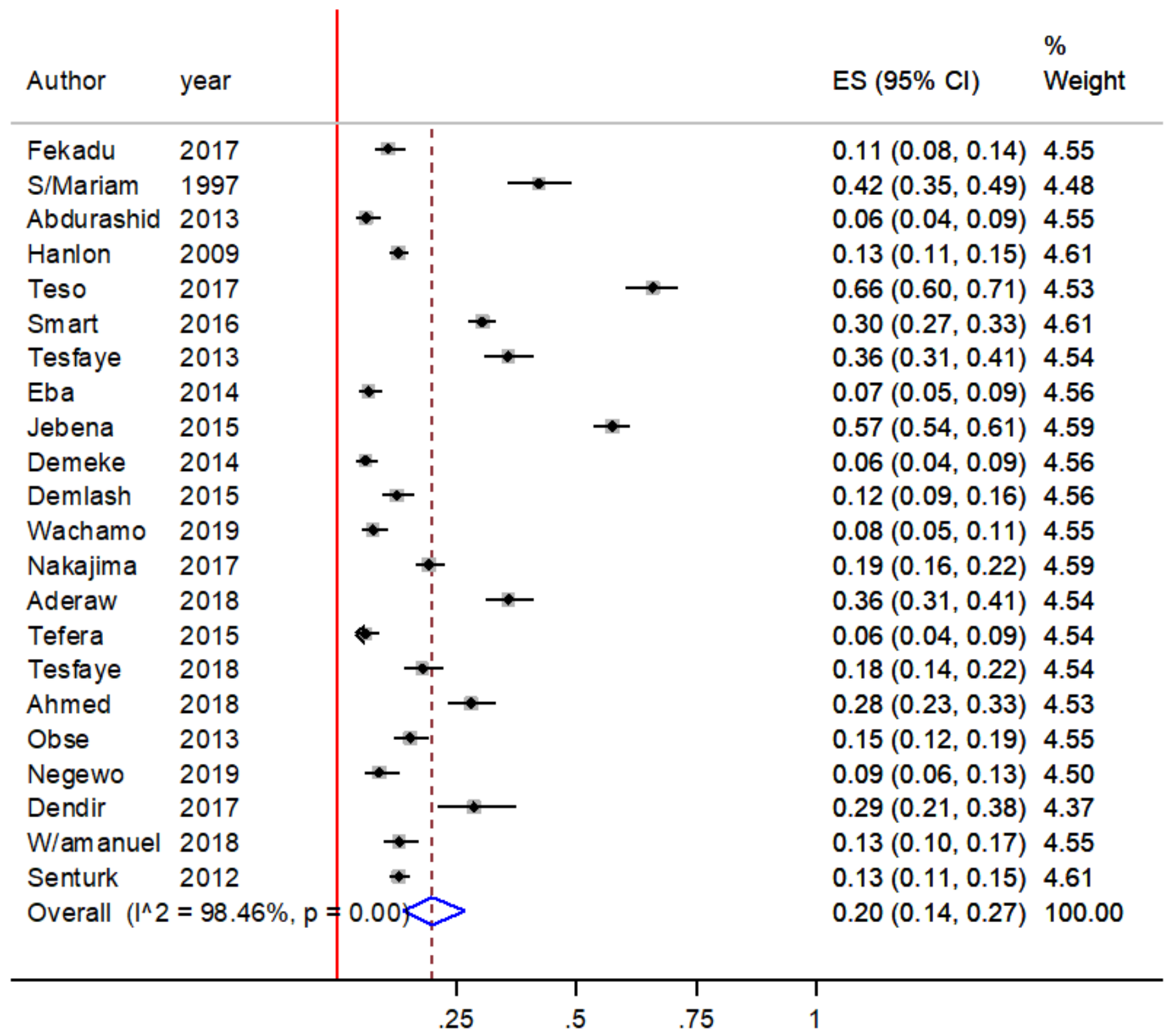

Figure 2

Forest plot presenting prevalence of khat chewing 
Funnel plot with pseudo 95\% confidence limits

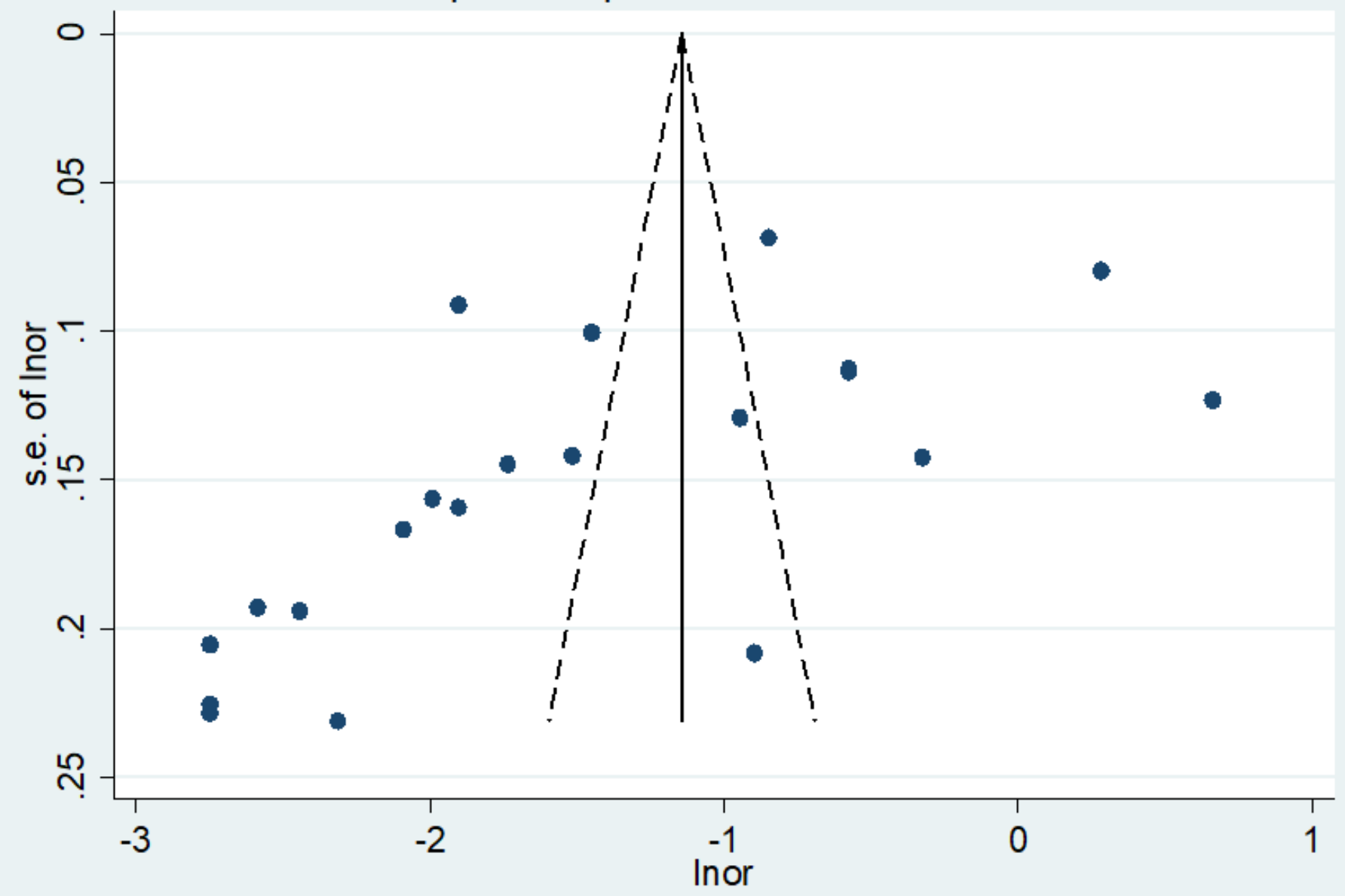

Figure 3

Funnel plot with pseudo $95 \%$ confidence interval that investigated the publication bias of the pooled prevalence of khat chewing.

\section{Supplementary Files}

This is a list of supplementary files associated with this preprint. Click to download.

- Additionalfiles.docx 